\title{
An innovative approach of incorporating a humanoid robot into teaching EFL learners with intellectual disabilities
}

\author{
Minoo Alemi ${ }^{*}$ (D) and Shirin Bahramipour ${ }^{2}$
}

\author{
* Correspondence: \\ minooalemi2000@yahoo.com \\ ${ }^{1}$ Department of English Language \\ Teaching, Faculty of Humanities, \\ Islamic sAzad University, West \\ Tehran Branch, Simaye Iran Ave, \\ Tehran, Iran \\ Full list of author information is \\ available at the end of the article
}

\begin{abstract}
The present case study investigated the probable effect of applying a humanoid robot as a teacher-assistant for learning and retention of English vocabulary among 10 Iranian foreign language learners with intellectual disabilities, more specifically Down syndrome. This method is a new trend in using technology to teach classes called Robot Assisted Language Learning (RALL). To this end, participants were divided into 2 groups of five, one with the help of the robot (RALL) and one without (non-RALL). Both groups received the same lessons to learn 40 English vocabulary in 8 sessions. To measure the results, three English tests were run at different times during the teaching sessions (a pre-test, post-test, and a delayed post-test). The independent sample t-test on gain scores from pre-test to post-test revealed that there was a significant difference between the gains of the RALL group ( $M=12.40)$ and the non-RALL group $(M=8.40)$, which indicates that RALL instruction had a large effect on the participants' English vocabulary improvement. Moreover, while both RALL and non-RALL groups retained the taught vocabulary, the RALL group showed a more satisfying result. The findings of this study demonstrate the positive effects of using a humanoid robot to facilitate vocabulary learning and retention among people with Down syndrome who have issues with both language learning and verbal short-term memory and need to learn through visual activities, gestures, and games. This study could be a starting point for a new line of research in second or foreign language instruction specific to people with Down syndrome.

Keywords: English vocabulary, Humanoid robot, Intellectual disabilities, Foreign language learners, RALL
\end{abstract}

\section{Introduction}

Technology is a tool that can help teachers and learners by making education easier and more motivating. Since cognitive ability is an important factor affecting the learning process, any kind of cognitive disorder can make learning more challenging. Down syndrome, one of the most common cognitive problems caused by a chromosomal disorder, was the focus of this study. Individuals with Down syndrome have some common physical characteristics and also cognitive delays that affect their learning process and social lives (Patterson, 2009). As the number of this population is increasing their needs must be taken into account along with those of typically developing people.

There have been many studies showing the positive effects of using technology to improve functional movement skills and cognitive abilities among people with

(c) The Author(s). 2019 Open Access This article is distributed under the terms of the Creative Commons Attribution 4.0 International License (http://creativecommons.org/licenses/by/4.0/), which permits unrestricted use, distribution, and reproduction in any medium, provided you give appropriate credit to the original author(s) and the source, provide a link to the Creative Commons license, and indicate if changes were made. 
cognitive disabilities such as people with autism. Moreover, many others studies conducted on typically-developing foreign language learners have all found Robot Assisted Language Learning (RALL) very promising (Alemi, Meghdari, \& Ghazisaedy 2014; Chang, Lee, Chao, Wang, \& Chen, 2010; Han, 2010; Lee et al., 2011). However, there seems to be a gap in the literature regarding the use of robots to teach a foreign language to individuals with Down syndrome. Learning a second language could help this population to improve their cognitive ability, to learn faster and more effectively, and also broaden their communication and self-confidence. Technology should be able to assist teachers and make learning more productive and easier for EFL learners with Down syndrome.

Accordingly, the current study was an attempt to investigate the probable effects of applying the Robot Assisted Language Learning (RALL) method to English vocabulary learning and retention among adult EFL learners with Down syndrome.

\section{Review of literature}

According to behaviorists, Second Language Acquisition (SLA) happens through a process of stimulus, response, and feedbacks. Krashen (1982) believes that learning is a conscious and explicit process while acquisition is a subconscious phenomenon like learning a mother language. Krashen also suggests that emotional factors such as motivation, personality and emotional state have an impact on the learning process. Therefore, the teacher ought to have general information about the students' proficiency level and their personality when assigning a task in order to help students experience a more relaxed environment to communicate in the target language. Cummins (2000) has also predicted that the amount of provided context and the level of difficulty can have an impact on the learned concept, skill or attitude. Another trendy approach is called Communicative Language Teaching (CLT). In this theory the focus is on developing language skills through communication and interacting in the target language in real-life situations and contexts.

Vocabulary learning is considered an essential part of foreign language learning. Gass and Selinker (2008) state the importance of vocabulary knowledge and pronunciation in communicating with native speakers and preventing communication breakdowns. During the last few decades, different methods and strategies have been developed and applied to make learning vocabulary easier and more effective (Gass \& Selinker, 2008; Schmitt \& McCarthy, 1997). Hatch and Brown (1995) identified five steps in vocabulary learning: source, a clear image, learning, a strong memory, and usage. According to Read (2004), vocabulary teaching and learning is divided into two categories: incidental and intentional vocabulary learning. Incidental learning is considered as learning vocabulary through extensive reading programs when the learners do not have access to a second language environment. However, intentional vocabulary learning refers to the rehearsal and memorization techniques used by learners to learn and retain vocabulary items explicitly and consciously (Schmitt \& McCarthy, 1997). The main criterion in this approach is learning and teaching specific vocabulary explicitly. Retention of the vocabulary is another significant factor in vocabulary acquisition and it has also received a great attention by many researchers (Leeke \& Shaw, 2000). A study by Brown, Waring, and Donkaewbua (2008) done on 5 EFL learners in Japan compared two types of "output condition" in which students talked about video scenes using the target 
words and an "input-dominant condition" in which vocabulary activities were conducted through questions about video scenes. The results revealed that students showed more retention in the output condition than the input dominant condition. In another research, Allen (1995) stated that vocabulary retention increases when they are taught with gestures. Also, Macedonia et al., 2011) compared two strategies (iconic and meaningless gestures) in vocabulary retention. The results revealed that meaningful gestures helped learners to significantly better retain the verbal material over time.

Considering the importance of English vocabulary and retention in SLA, researchers and educators have been investigating the effects of technology-based education on vocabulary learning skill. Many studies have proven the advantages of Computer Assisted Language Learning (CALL) and Mobile Assisted Language Learning (MALL) as two main strategies (Alemi, Anani Sarab \& Lari, 2012; Holden \& Sykes, 2013; Taguchi \& Sykes, 2013). However, other studies have proven the drawbacks of CALL as not being tangible and interactive enough for learners (Chang et al., 2010; Hegarty, 2004; Xie et al., 2008). Therefore, researchers started research on a new trend in language teaching called Robot Assisted Language Learning (RALL). According to Thurn (2004), robots have the advantage of being autonomous and interactive with humans, which is an important factor in language teaching. In addition, according to Fink (2012), robots with the ability to play the role of a native speaker in teaching classes are able to provide the necessary human robot interaction (HRI), and are also more successful in communicating due to their friendly appearance and ability to attract people. Educational robots fall into three categories: Tele-operated robots, autonomous robots, and transformed robots (Han, 2012). Tele-operated robots are operated through a remote control by the teacher, while autonomous robots feature artificial intelligence and are programmed to do desired actions. Transformed robots, on the other hand, can be operated through both a remote control and pre-programming with the ability to switch between these two different modes of use. Samples of these robots are presented in Figs. 1, 2, and 3.

Kanda et al., 2004 used an autonomous robot called ROBOVIE in Japanese elementary schools, and their study proved the positive effect of interacting with the robot in the target language on participants' English learning. Hyun, Kim, Jang, and Park (2008) have proven RALL to improve vocabulary learning of preschoolers. Chang et al. (2010) have also investigated the effects of using RALL by designing five robot modes including: story telling mode, oral reading mode, cheerleader mode, action command mode, and question-and-answer mode. Their findings showed that the students were more encouraged to interact in the class and observed the class more carefully when the robot was presenting teaching activities Park et al., 2011) also found students' interaction with robots to be helpful in both increasing student motivation and facilitating their language learning process. Another research conducted in Iran by the Alemi, Meghdari, \& Ghazisaedy (2014) used a humanoid NAO robot to study its effects on English vocabulary acquisition and retention among Iranian junior high school students. The findings revealed that students were more motivated to participate in some tasks, their problem-solving abilities developed, and their anxiety level reduced (Alemi, Meghdari, Basiri, \& Taheri 2015a; Alemi, Meghdari \& Ghazisaedy 2015b; Alemi, Meghdari, \& Haeri 2017) also investigated 19 preschool Iranian EFL learners' attitude towards RALL instruction. Their findings indicated an increase in children's motivation by interacting with the robot and a 


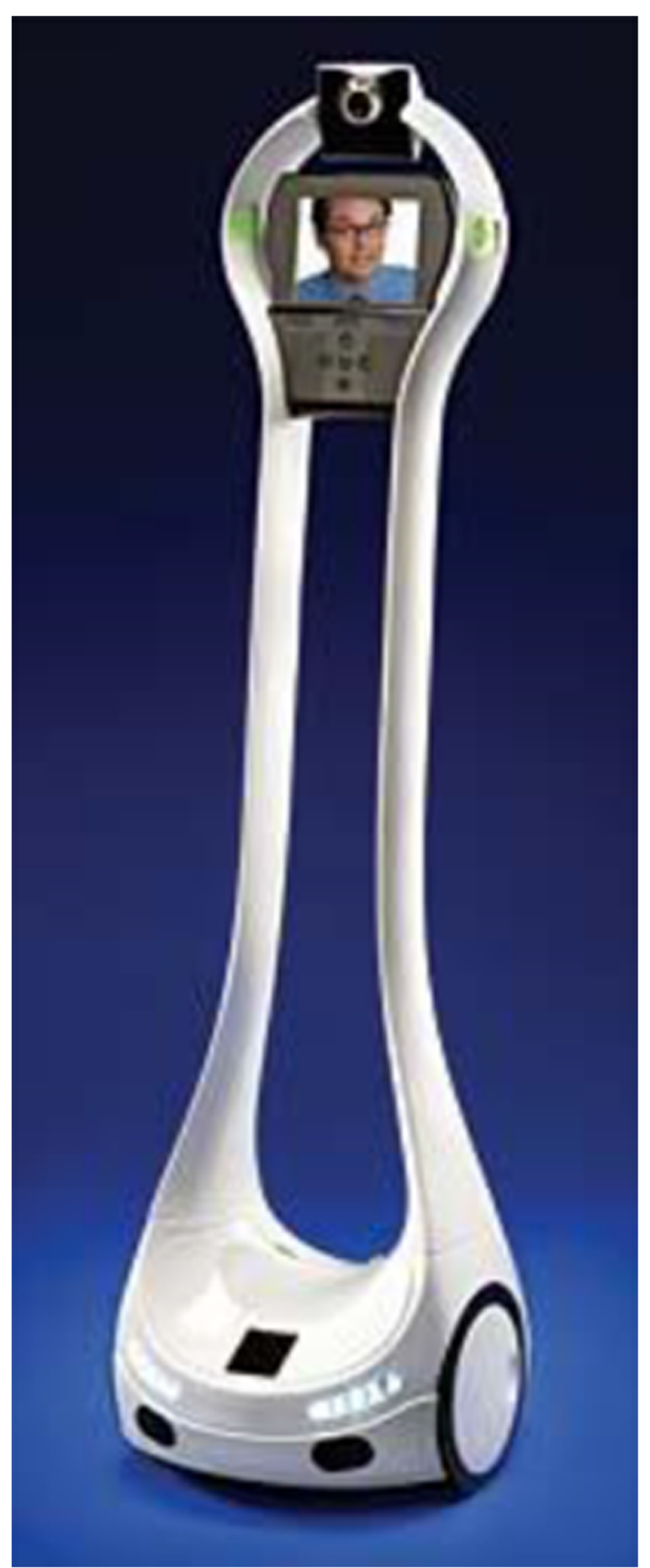

Fig. 1 Tele-operated robot

decrease in their anxiety due to the friendly atmosphere provided by the presence of the robot in the class.

Starting from the mid-1990s and early 2000s the field of human robot interaction (HRI) has been motivating researchers from different fields of studies, such as robotics, psychology, cognitive science, and natural language, to work together and conduct 


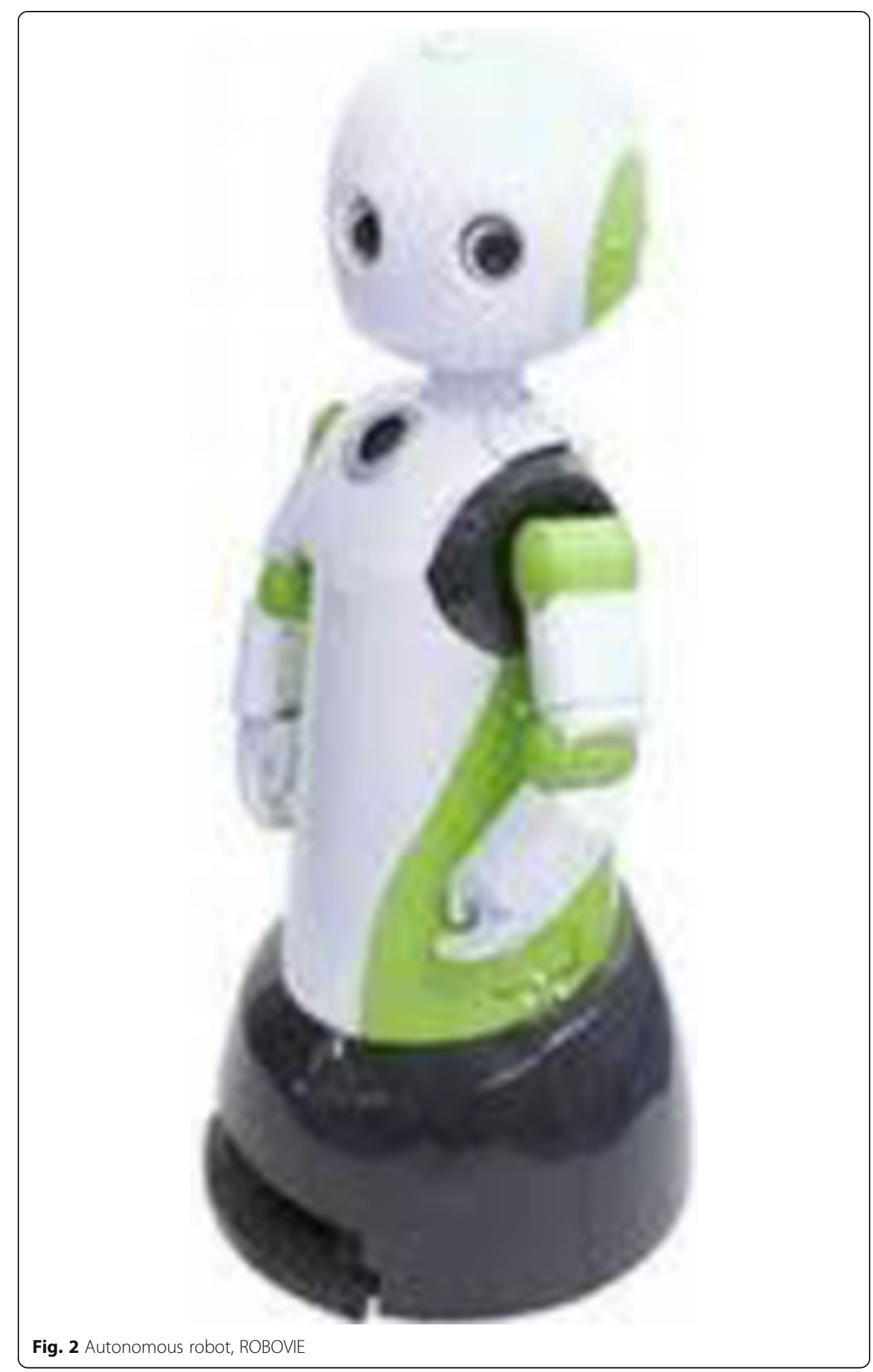

many cross-disciplinary studies (Goodrich \& Schultz, 2007). An example of such crossdisciplinary research is a study by Dautenhahn and Billard (2002) on 8 to 12-year-old autistic children using a robot called ESRA (Fig. 4) as an interactive toy which revealed that the participants were motivated to interact with the robot. 


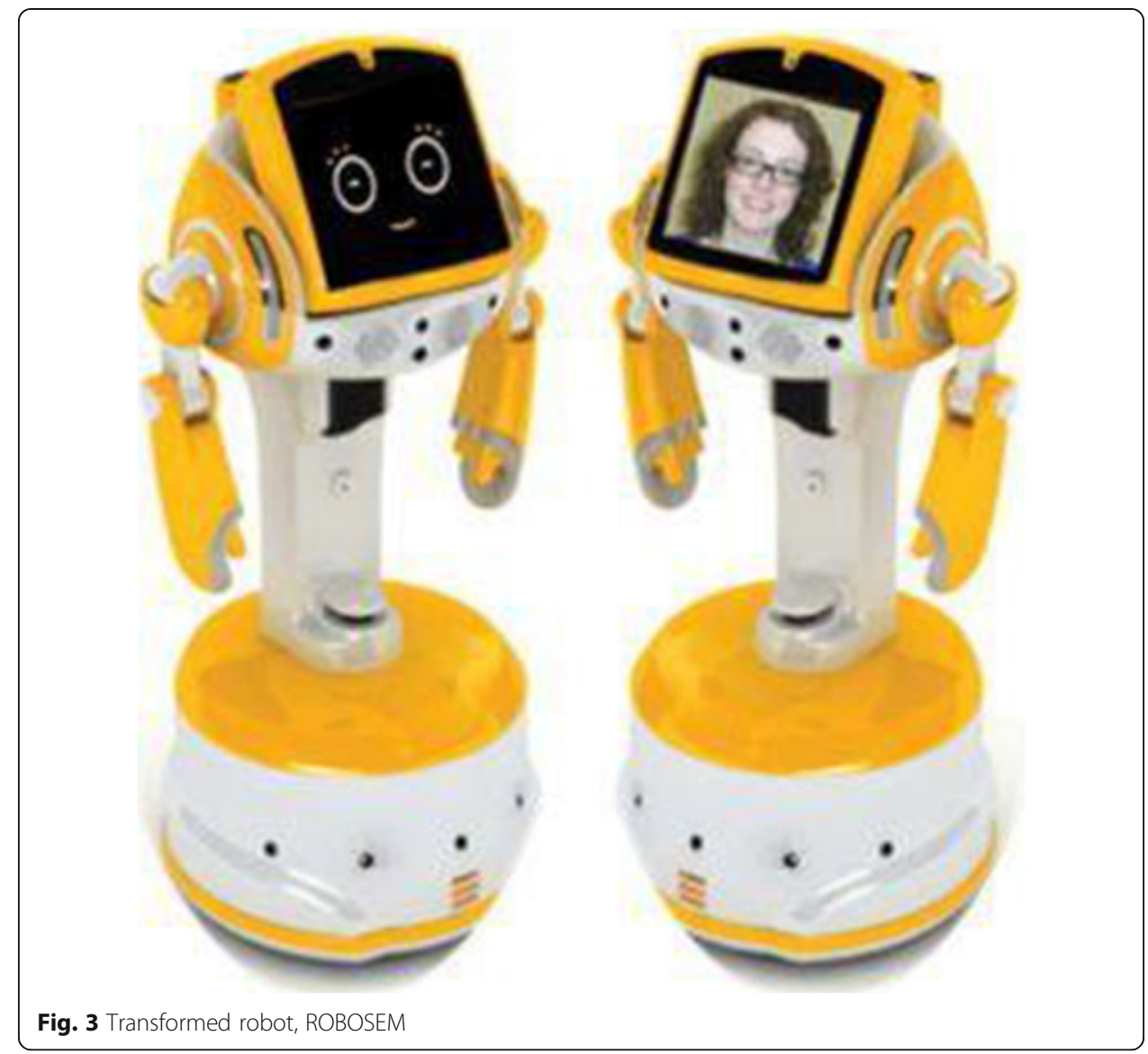

A study by the Alemi, Meghdari, Pouretemad, \& Taheri 2013a; Alemi, Meghdari, \& Taheri (2013b) used two humanoid robots (NAO and Alice, see Fig. 5) for treatment of individuals with autism in Iran through playing imitation games and other therapeutic activities. The results represented positive effects on autistic children's motivation to participate in the therapeutic sessions by improving their eye-contact abilities and eagerness to interact with the robots.

Another study conducted by the Alemi (2015a, b) focused on teaching English vocabulary to autistic children and the results revealed large gains in learning and retention based on their performances on tests. In addition, the participants showed less

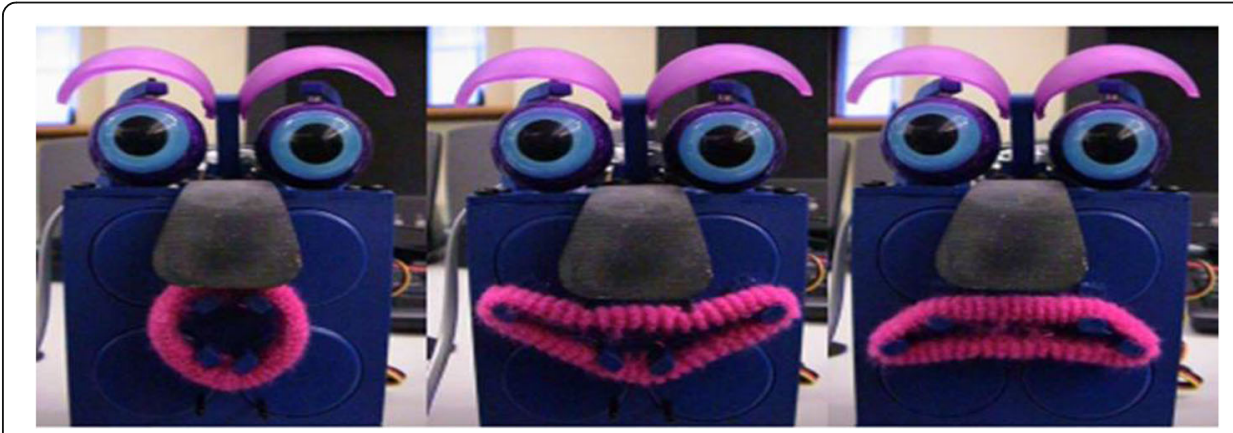

Fig. 4 The ESRA robot 

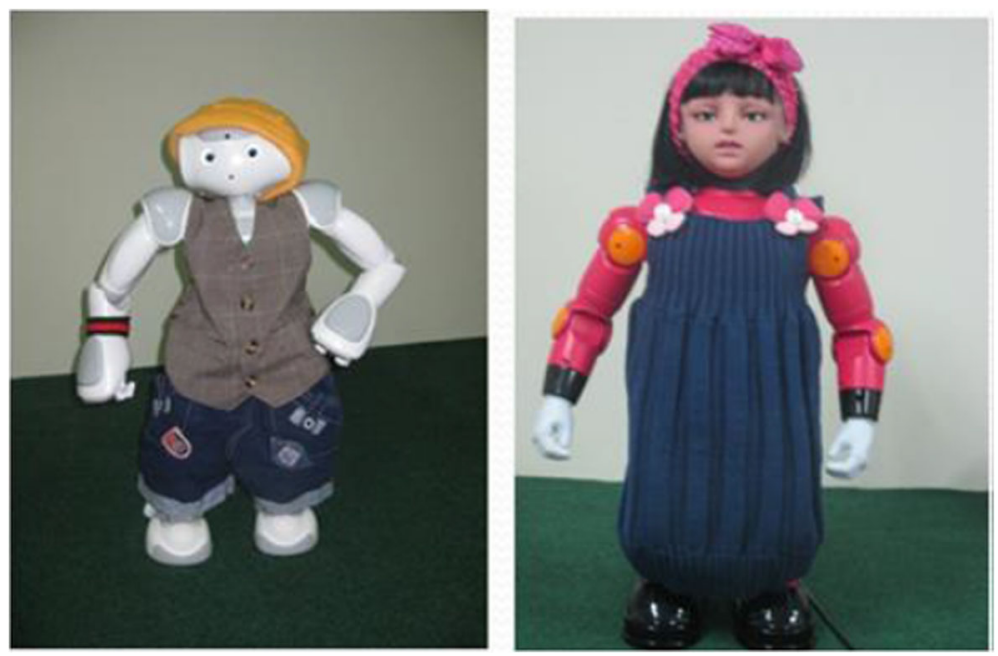

Fig. 5 The NAO and Alice robot

anxiety and more motivation to learn English. They also observed an increase in the children's joint attention when using the robot.

As in other cases of people with cognitive disorders, those with Down syndrome (DS) also seem to have the need for assistance in language learning. Although they are believed to be good communicators, language learning delay due to their cognitive delay is a typical characteristic among them (Abbeduto, Chapman, Fletcher, \& Miller, 2005; Chapman, 2003; Chapman \& Hesketh, 2000). Most children with DS are late in uttering their first words, and their vocabulary development is slower than for neurotypical children. They also have problems with learning and saying grammatically correct sentences. Their speech is usually limited to some telegraphic utterances which are not pronounced very clearly due to their difficulties in pronunciation (Bray \& Woolnough, 1988). A study by Yoder, Woynaroski, Fey, Warren, and Gardner (2015) on preschoolers with DS found that daily communication and language therapy had more favorable spoken vocabulary outcomes than weekly therapy sessions. Therefore, it can be said that having early continuous therapy sessions can help these people to develop their language learning ability. Regarding the short-term memory ability of children with Down syndrome, they experience a low ability to hold and process verbal information instead preferring visual information and this makes it difficult for them to learn new words and sentences (Jarrold and Baddeley, 2001). This information has caused educators and teachers to use more visual supports such as pictures, toys and prints in order to make use of their visual skills and improve their learning abilities. In the case of technology-based education, a case study by Lehmann, Iacono, Dautenhahn, Marti, and Robins, 2014) used a humanoid robot called KASPAR and the mobile robotic platform IROMEC to examine the development and improvement of social skills of a child with Down syndrome. The results showed that the KASPAR robot, having the advantage of being child-like which simulates social behavior, helped the child with some interactions such as looking at the researcher, imitation and vocalization while the IROMEC robot was a help because it provided the stability to allow the child to touch the robot. Therefore, it can be said that robots can be used as facilitators for these individuals to have more scholastic and social communication. 
In this study, since we could not find volunteer children with DS who could make up a homogeneous group, we decided to do research on a homogeneous group of adults with DS who had started learning English individually while we didn't find any study on adults with DS in this area in the literature.

\section{Method}

The focus of the current case study was to investigate the effects using a humanoid robot as a teacher-assistant can have on English vocabulary learning development and retention among individuals with Down syndrome. To this end, the researchers taught a pre-designed syllabus to two different groups of five, one with and the other without the assistance of the robot. The robot was pre-programmed for each and every teaching scenario for the RALL group. A pre-test, immediate post-test, and a delayed post-test were designed to measure the English vocabulary learning gains of each group during the course of the program. Detailed descriptions of the participants, instruments, data collection procedure, and data analysis are presented below.

\section{Participants}

The Down Syndrome Center of Iran (DSCI) offered the researcher a list of 10 participants who made as homogenous a group as possible in terms of ages, level of cognitive abilities and their English knowledge based on the records of the students. For the next step, they agreed to let the researcher observe some of their English classes to get to know the participants and their special challenges in the class and also to be prepared for the teaching sessions. It is worth mentioning that all of the participants in this study were taking individual English classes at DSCI and each received a different teaching strategy based on their abilities and personal characteristics, and they studied different English materials which were generally focused on vocabulary learning or reading. Also, all of the participants had little background in English which was proven by their performances in the English pre-test. They were randomly divided into two groups of five (control and experimental). They were all adults with an average age of 30 (4 females and 6 males) and had little knowledge of English. The first five subjects are for RALL group and the next five ones are for non-RALL group as shown in Table 1.

\section{Instruments}

To carry out the current case study, three English tests were used to investigate the improvement of English vocabulary learning and retention at different times during the instruction: a pre-test, immediate post-test and a delayed post-test. The scores of the tests were analyzed through independent sample t-test on SPSS. The humanoid robot used in teaching classes for the RALL group was the main tool for investigating the results.

Table 1 RALL and non-RALL Participants' Information

\begin{tabular}{lll}
\hline Participants S1 S2 S3 & S4 S5 S6 & S7 S8 S9 S10 \\
\hline Age 313630 & 302424 & 33302531 \\
Gender F F F & M M F & M M M M \\
\hline
\end{tabular}




\section{English tests}

The tests consisted of two parts. The first part was a matching activity including 24 vocabulary items and the second part was 4 functional vocabularies which participants needed to act on. The pre-test was administered before the teaching sessions first to make sure that all the participants were more or less at same levels to insure that the classes are as homogeneous as possible; and second, to compare the results with the post-test to measure the group's English vocabulary learning advances. The delayed post-test was run 2 weeks after the immediate post-test. The aim of the delayed posttest was to investigate how persistent the participant's learning gains were (See all the tests in the Additional file 1).

\section{Teaching materials}

Due to the fact that the participants were studying different sources of English in their private English classes at DSCI, and in order to have a specific source as a teaching material, the researcher provided a list of 40 vocabulary based on usage and participants' needs. The teaching syllabus for each session consisted of 5 vocabularies. The participants learned 40 vocabularies during 8 one-hour teaching sessions. The flashcards of the vocabulary items or in some cases the real objects were also used among other teaching instruments for two major reasons: first, they would be used as fast efficient reviews of the pre-taught vocabulary items with the students before teaching new materials. Second, by using these items students would get the chance to have face to face interaction with NIMA the teaching assistant robot. Since the participants did not have a source to study at home, the researcher also developed a homework assignment including the taught vocabulary for the students to do at home after each session. Therefore, both parents and students would have access to the teaching source and also could practice at home.

\section{Humanoid robot}

The humanoid robot NAO (the Robocup version) developed by Aldebaran Robotics (Fig. 6) was renamed NIMA (a Persian name) by CEDRA for use in Iranian context and used as a teacher-assistant in this study.

Choregraphe is the visual graphical programming language of NIMA. It is a userfriendly software which has a library of predefined behaviors. Many steps need to be taken to develop an action, say a dance, for NIMA. This software is equipped with a Webot for NAO simulation. The Webot allows for testing the created behavior on a stimulated robot in a $3 \mathrm{D}$ environment. This makes it possible to do the programming in software installed on a computer without the presence of the robot itself (Fig. 7).

Additionally, Choregraphe makes it possible to make changes to NIMA's voice and pitch and even its pace of talking. The voice chosen for NIMA in this study was a 10year old boy's voice with a moderate pace to make its speech understandable for the students. The humanoid robot was used as a teacher-assistant which had the role of motivating students and attracting their attention. A step-by-step lesson plan enabled the researcher to write and design exact pre-planned and pre-programmed lines and movements for NIMA. Accordingly, the classroom scenarios provided a guideline for programming NIMA via the Choreograph software. 

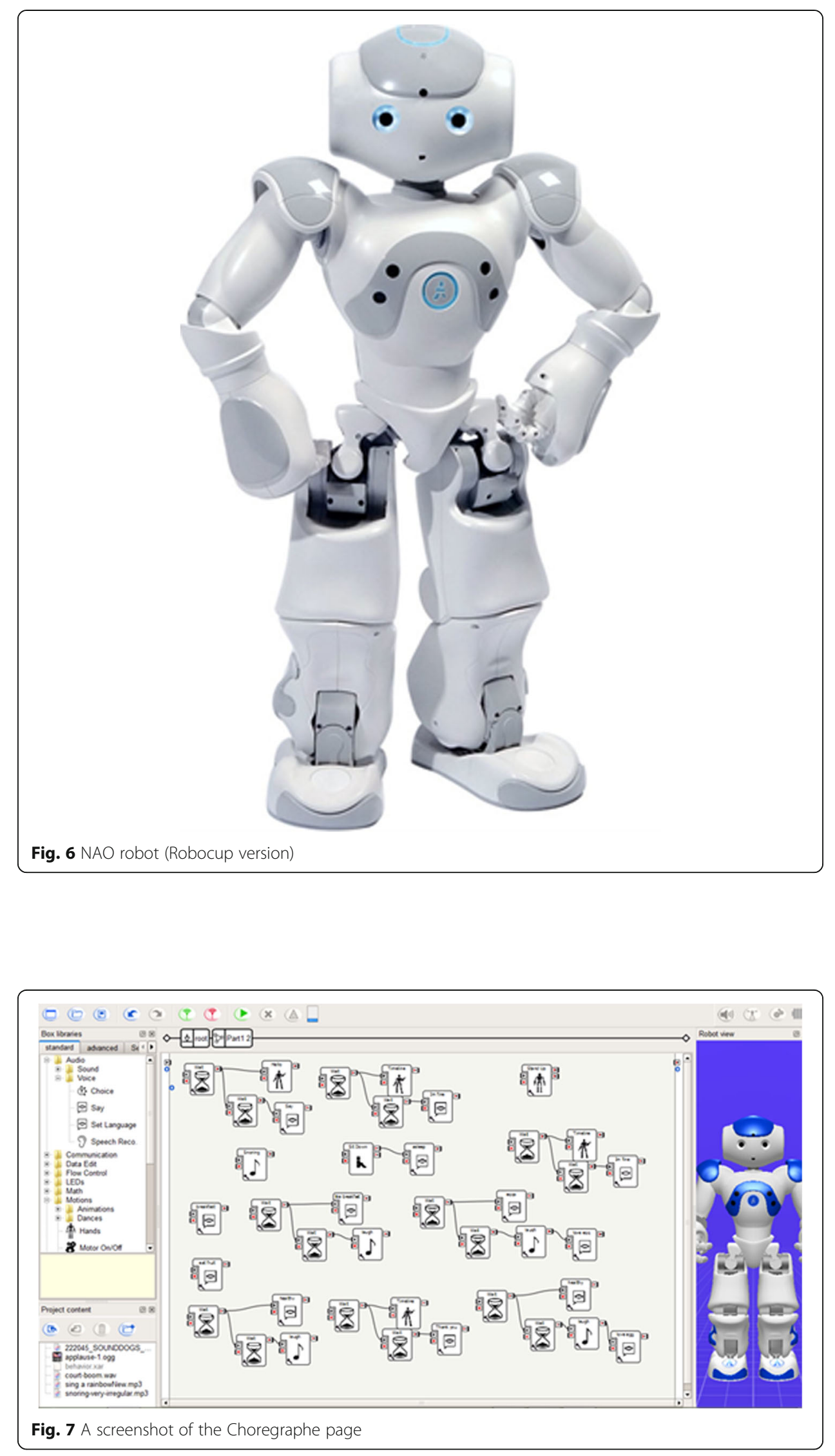
It is worth mentioning that the robot was pre-programmed with a fixed sequence.

There were user interactions involving the teacher/students/robot in all the teaching sessions which were performed via a text-to-speech engine, speech recognition and the image recognition abilities of the robot, and the robot's responses were preprogrammed as per the script of the activity. There was no personalization/adaptation in the robot's presentation of the vocabulary due to its limited technical abilities.

Procedure To collect the data, the 10 participants were randomly divided into two groups of 5 students in RALL and non-RALL groups randomly. RALL classes were conducted at the social-cognitive robotics lab at Sharif University of Technology and the non-RALL sessions were held at the DSCI. At the beginning, a pre-test was administrated before the first session for both RALL and non-RALL group based on the designed syllabus which their scores revealed the level of participants' vocabulary knowledge and to make as homogenous groups as possible. After 8 teaching sessions, a post-test was run for both groups to identify the level of participants' vocabulary learning gains. Two weeks after the post-test, a delayed post-test was run to measure the retention of the participants on the taught vocabularies.

We had eight equal one-hour long teaching sessions two days a week for each group. The RALL program had the advantage of interacting with the humanoid robot in addition to the teacher, whereas the non-RALL group was managed only by the teacher who was also the researcher. After introducing the program and its purpose to the participants' parents, the pre-test was administrated. Because most of the students were not able to read or understand the questions and did not have an experience of taking English exams, the teacher at DSCI helped the researcher to run the pre-test and the instructions were translated and explained in Farsi. Each session would start with a warm up which was either a song or a simple game based on the students' interest and needs. Before holding each of the RALL program sessions, NIMA would be programmed via the Choregraphe software with the help and under the supervision of social robotics assistants at CEDRA. The teacher would practice the scenario with NIMA before each session in the presence of an operator to identify any problems in NIMA's programming that needed to be resolved and would make changes in NIMA's movements and lines if necessary. It should be noted that in order to encourage students to interact with NIMA and also to provide a friendly atmosphere, NIMA was introduced to participants as a 10-year-old friend who speaks English. Because people with Down syndrome are known to be good communicators, one of the modes the researcher applied for NIMA as an assistant was to program it to interact with the teacher and/or students through a conversation using the vocabularies.

As mentioned above, the teaching materials in the classes were 40 vocabularies which were selected based on the participants' needs. These 40 vocabularies made up 8 teaching scenarios (five vocabularies each session). Each lesson consisted of five vocabulary contextualized in a short conversation between NIMA and the students or the teacher, the learners would learn the usage of the new words in their conversations. It should be noted that to help the students follow up the conversation, the teacher would sometimes speak Farsi or use some gestures to teach meanings. The agenda of each session, however, was quite the same for both RALL and non-RALL groups and is presented in Table 2. 
Table 2 The topics of the sessions

\begin{tabular}{ll}
\hline Session & Topics \\
\hline Orientation & Pre-test / Introduction of the program \\
Session 1 & Nice to meet you. \\
Session 2 & Do what I do \\
Session 3 & Let's share what we have \\
Session 4 & Let's party \\
Session 5 & Ab-Robot (WATERobot) \\
Session 6 & I can draw \\
Session 7 & I am healthy \\
Session 8 & Let's travel / Post-test \\
Session 9 & Delayed Post-test \\
\hline
\end{tabular}

The detailed instruction is described below. Everything was the same in the nonRALL group with the teacher doing all the activities without the help of the NIMA robot. It is worth mentioning that all sessions have been recorded to analyze the participants' motivation and eagerness in both groups.

In the first session, NIMA and the participants were introduced as friends and had a conversation including their names and ages and talked about their abilities. Students were highly encouraged to come and touch shake hands with the robot and talk to it (Fig. 8), which was a positive move. To present NIMA and his abilities to the students, some modes were preprogrammed into NIMA such as dancing and playing music or kicking a ball. In non-RALL group the teacher and the students performed the whole scenario.

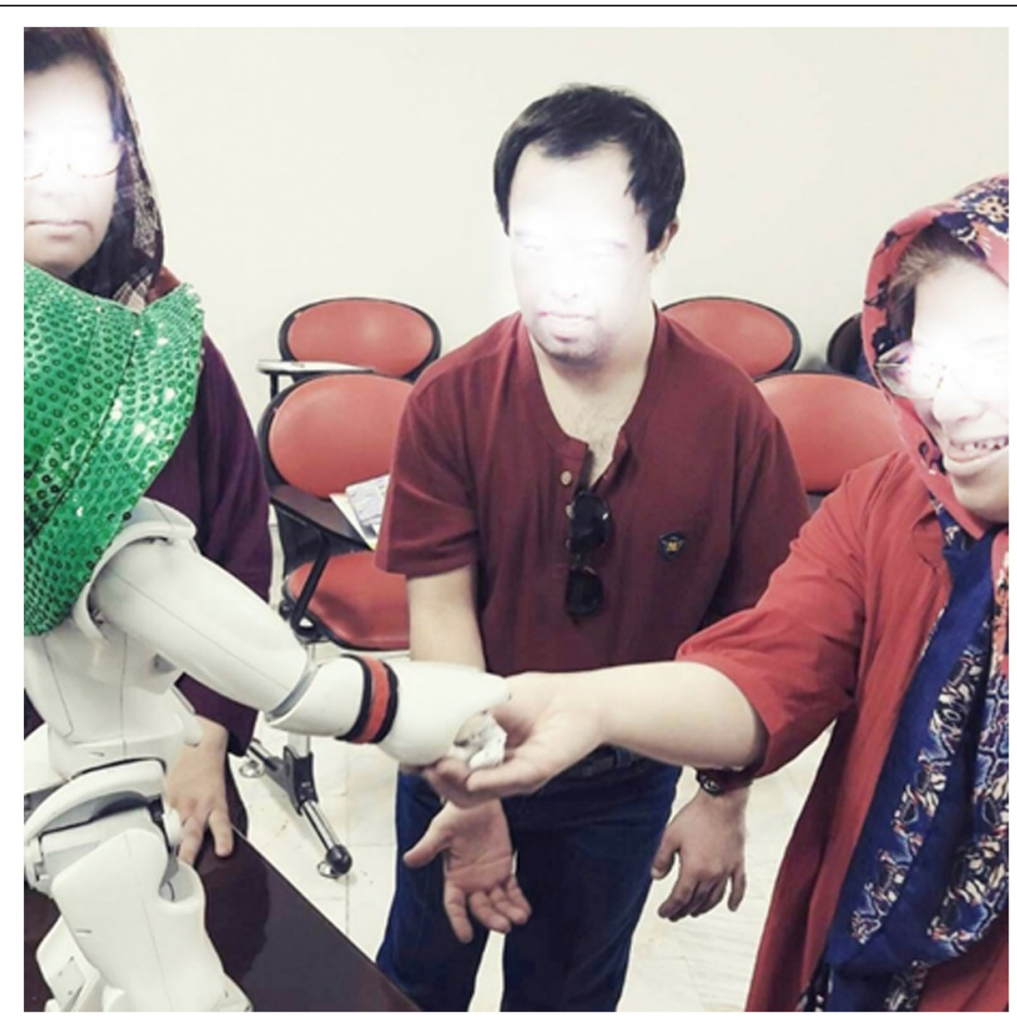

Fig. 8 Students shaking hands with NIMA 
In session two, the teacher first showed the students some flashcards to teach the vocabulary. They would look at the flashcards and repeat the words after the teacher. Next, they would play a game in which NIMA would act out the vocabulary and the students would guess what he was doing. To have more fun, students were divided in two groups and each group would say a word and the other group would act on it. Here is a picture of NIMA and students doing the activity (Fig. 9).

In session three, students were told to bring some food to class. In this scenario NIMA acted as a classmate who had forgotten his food and the participants' shared their food with him. Any time a student shared something with NIMA they received positive feedback using the taught vocabulary. This would encourage the students to have more interaction with the robot. Here is an example:

$\mathrm{N}$ : I don't have food.

S: shares apple.

N: Thank you. Hmm... Delicious. You are kind.

To teach the word "delicious", besides showing the related picture, the teacher would do a gesture of eating something delicious and ask the students to repeat the word and do the same. This strategy helped students remember the words as they saw the teacher do the gesture.

Session four's scenario was written based on birthday vocabulary. In this case, a birthday song and a dance mode were uploaded and programmed in NIMA. Students were surprised by a birthday cake and they held a party in which NIMA had conversations with students and sang for them. The teacher used several objects or did some gestures, like blowing out candles and cutting the cake with a knife, to teach the related vocabulary and the students repeated the words and gestures together.

In session five, students watched a video clip named Abrobot (a short video clip in Persian made by the social robotic team at SUT which focuses on water conservation).

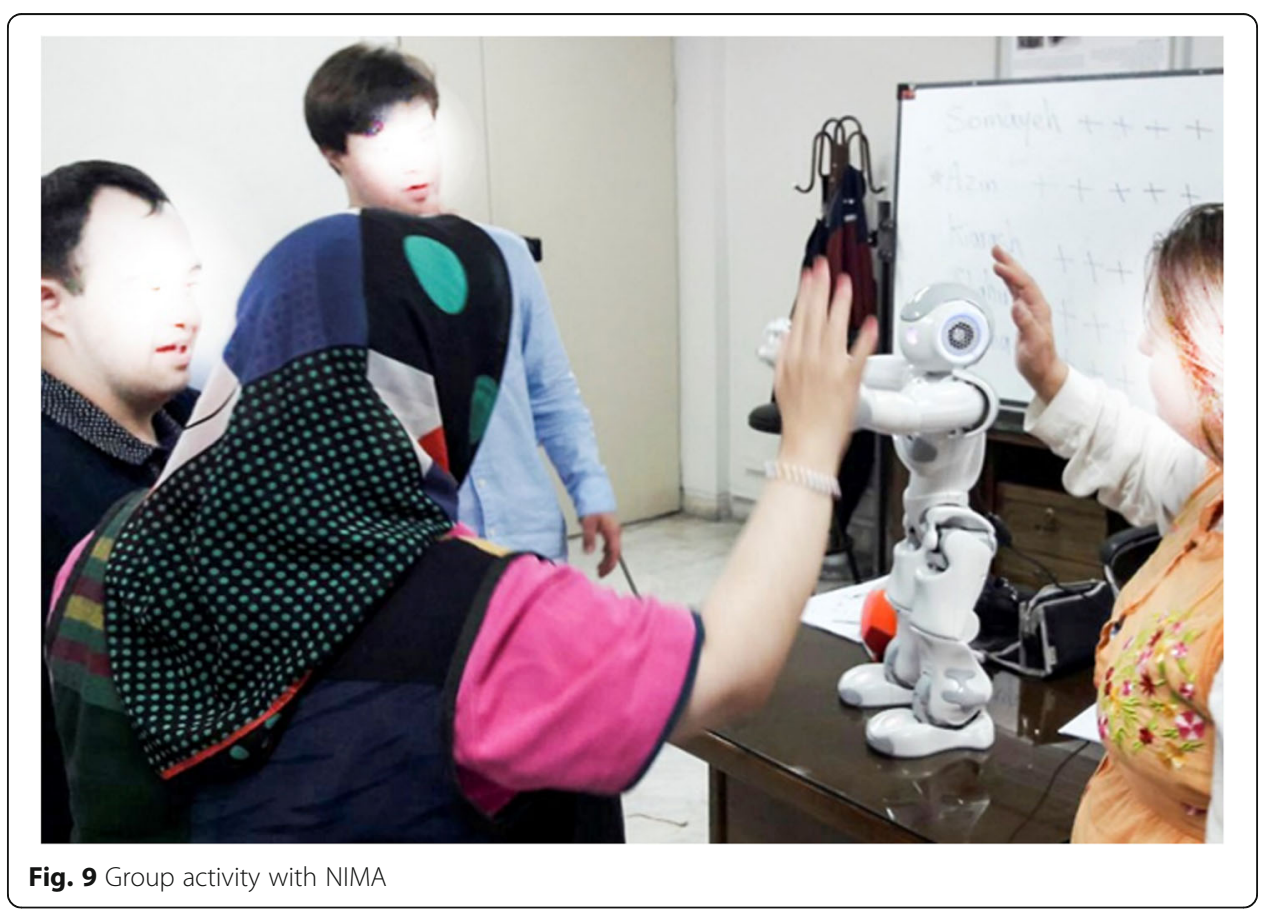


Students watched the video twice. The first time to get the general idea, and the second time the teacher would pause the video on some actions and ask NIMA to say a word. The teacher would also show a related picture of the word to the class and ask the students to repeat the words chorally after NIMA. At the end of the session, students and NIMA played a game practicing the vocabulary. For instance, the teacher would say some words in Farsi and the students would translate the word in English and also act on it.

In session six, the students were asked to bring painting notebooks to class. The teacher drew a picture on the board and NIMA asked the students using imperative sentences to do the same, for example "draw a flower" to teach the word "draw". After repeating this activity several times, other new words would be substituted in the sentences such as "draw a circle" to teach the word "circle" for instance (Fig. 10). This activity seemed to make students try to be more creative and make some pictures out of the shapes.

In session seven, the vocabularies were related to the concept of being healthy. The teacher would have a short conversation with NIMA to teach the vocabulary. The word "healthy" was the adjective in this lesson and it was taught through a conversation between the teacher and NIMA about eating a healthy breakfast. The teacher also brought some fruit to the class and shared it with the students.

T: NIMA? What do you eat for breakfast?

$\mathrm{N}$ : Eggs. I love eggs.

$\mathrm{T}$ : Excellent. What else?

N: I eat fruit, too.

T: Fruit? Great. So you are healthy.

In the last session, NIMA was in a scenario in which he was going to travel. So, he had a ticket and would raise it and say "I have a ticket." The students would know the meaning by looking at the ticket. The teacher would also ask students to help NIMA pack his bag

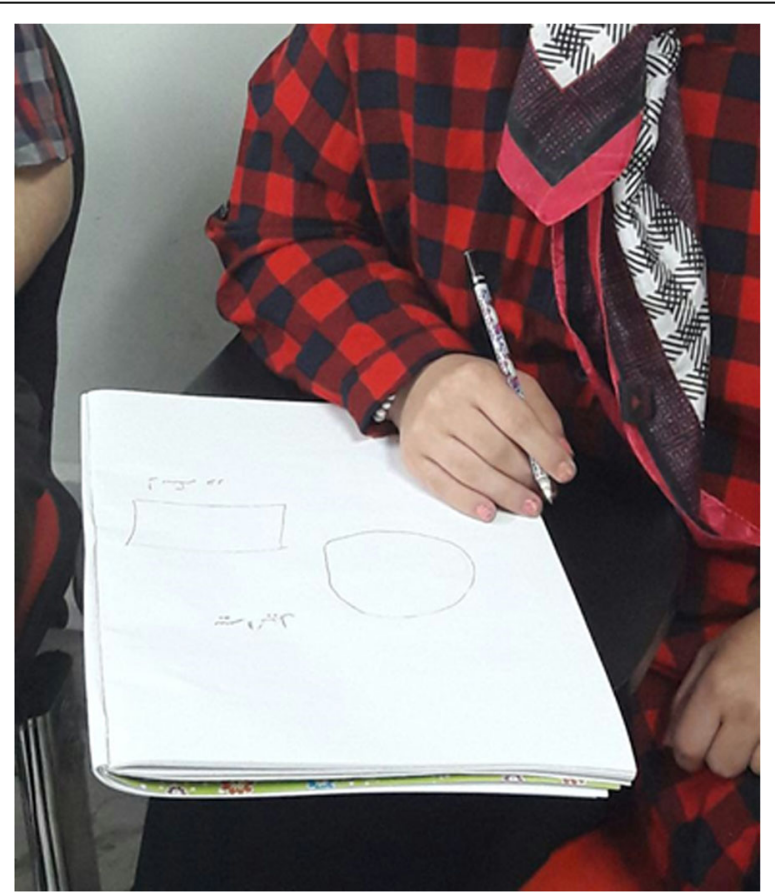

Fig. 10 A student's drawing shapes 
to teach them the word "help" in the context. At the end of the session, students reviewed all vocabulary by playing a game and group activities. They seemed to be unhappy saying good-bye to NIMA and came to him one by one to say good-bye and hug him. This was proof that the participants enjoyed the classes and interacting with the robot.

\section{Data analysis}

In order to analyze the data, the scores gained at the time of pre-test, post-test and the delayed post-test were measured and compared. Two independent sample t-test were run on gain scores of participants in both groups at different times of testing. One at the point of pre-test to post-test and another one on the gain scores from post-test to delayed posttest. It should be said that another independent sample $t$-test was implemented prior to the main analysis to compare the pre-test scores of students in the two groups, and no pretreatment difference was found, $t(8)=1.3, p=.20$, equal variance assumed.

\section{Results}

This study aimed to investigate the effects of RALL on English vocabulary learning and retention among people with DS. Therefore, descriptive statistics of the RALL and non-RALL groups was conducted at different times of testing (see Table 3).

As Table 3 represents, both groups' mean scores increased from pre-test to post-test (RALL: $M=14: 00$ to $M=26.40$, non-RALL: $M=16.40$ to $M=24.80$ ). Also, both groups mean scores decreased from post-test to the delayed post-test. To investigate the difference between the pre-test and the post-test as well as that of post-test to delayed posttest of students in both RALL and non-RALL groups, a descriptive analysis and an independent sample $t$-test were also conducted on the gain scores (the deviation score) as shown in Tables 4 and 5.

The results of the independent sample $t$-test on gain scores of English vocabulary learning from the pre-test to the post-test showed that there was a significant difference between the gains of the RALL group $(M=12.40, S D=1.51)$ and the non-RALL group $(M=8.40, S D=1.81), t(8)=3.78, p=.00$, equal variance assumed (see Tables $4 \& 5)$ with the Cohen's d effect size of 2.36 which was considered a large effect. It can be said that students in the RALL group had far more advances from the pre-test to the posttest in comparison with that of their counterparts in the non-RALL group, and this is due to presence of robot as a T.A in the class.

The results of the independent sample $t$-test on gain scores of English vocabulary learning from the post-test to the delayed post-test indicated that there was not a significant difference between the gains of the RALL group $(M=-1.20, S D=2.17)$ and

Table 3 Descriptive Statistics of RALL and non-RALL Groups in Different Times of Testing

\begin{tabular}{lllllllll}
\hline & & $N$ & Mean & Std. Deviation & Skewness & Std. Error & Kurtosis & Std. Error \\
\hline RALL & Pre-test & 5.00 & 14.00 & 2.12 & 0.52 & 0.91 & -0.96 & 2.00 \\
& Post-test & 5.00 & 26.40 & 1.14 & 0.40 & 0.91 & -0.18 & 2.00 \\
& Delayed post-test & 5.00 & 25.20 & 1.92 & -1.52 & 0.91 & 2.61 & 2.00 \\
\multirow{2}{*}{ Non-RALL } & Pre-test & 5.00 & 16.40 & 3.21 & -0.75 & 0.91 & -2.04 & 2.00 \\
& Post-test & 5.00 & 24.80 & 2.59 & 0.36 & 0.91 & -2.41 & 2.00 \\
& Delayed post-test & 5.00 & 22.80 & 4.32 & 0.04 & 0.91 & -2.37 & 2.00 \\
\hline
\end{tabular}


Table 4 Descriptive Statistics of English Vocabulary Gain Scores of RALL and non-RALL Groups

\begin{tabular}{llllll}
\hline & & N & Mean & Std. Deviation & Std. Error Mean \\
\hline RALL & Pre-test to post-test & 5.00 & 12.40 & 1.51 & 0.67 \\
& Post-test to delayed post-test & 5.00 & -1.20 & 2.17 & 0.96 \\
\multirow{2}{*}{ Non-RALL } & Pre-test to post-test & 5.00 & 8.40 & 1.81 & 0.81 \\
& Post-test to delayed post-test & 5.00 & -2.00 & 2.00 & 0.89 \\
\hline
\end{tabular}

the non-RALL group $(M=-2.00, S D=2.00), t(8)=.61, p=.56$, equal variance assumed (See Tables $4 \& 5$ ). It can be said that both groups had some decrease from the posttest to the delayed post-test but there was no statistically significant difference between them. This result is indicative of both groups' success to remember the taught vocabulary, while the RALL group's scores were more satisfactory due to more retention in the RALL group.

\section{Discussion}

As the focus of this study was on English vocabulary learning and retention among EFL learners with Down syndrome, the main factors that were taken into account were the personal characteristics of these people and the problems they face learning a language. People with Down syndrome have been proven to be good communicators but they need early intervention to acquire some language skills and extra time as they can acquire the language slowly (Sandall, Schwartz, 2002). As learning English as a foreign language is almost a new course for the participants in this group, applying a useful intervention could help motivate them to learn easier and faster. It should also be noted that these participants did not have previous experience of being in English group activities which could have made them feel more anxious or distracted during the intervention. Since language learning is a conscious and explicit process, based on Krashen's theory, it can be affected by the learners' emotional factors such as personal characteristics, motivation and anxiety level. This was an important issue in this study, since individuals with DS have a delay in their language development and their personal characteristics vary from person to person from mild to moderate (Patterson, 2009).

Table 5 Independent Sample t-test of Gain Scores from Pre-test to Post-test and Post-test to Delayed Post-test

\begin{tabular}{|c|c|c|c|c|c|c|c|c|c|}
\hline & & \multicolumn{2}{|c|}{$\begin{array}{l}\text { Levene's } \\
\text { Test for } \\
\text { Equality of } \\
\text { Variances }\end{array}$} & \multirow{3}{*}{$\mathrm{T}$} & \multirow{3}{*}{$d f$} & \multirow{3}{*}{$\begin{array}{l}\text { Sig. } \\
\text { (2- } \\
\text { tailed) }\end{array}$} & \multirow{3}{*}{$\begin{array}{l}\text { Std. Error } \\
\text { Difference }\end{array}$} & \multirow{2}{*}{\multicolumn{2}{|c|}{$\begin{array}{l}95 \% \\
\text { Confidence } \\
\text { Interval of the } \\
\text { Difference }\end{array}$}} \\
\hline & & \multirow[t]{2}{*}{$\mathrm{F}$} & \multirow[t]{2}{*}{ Sig. } & & & & & & \\
\hline & & & & & & & & Lower & Uppe \\
\hline $\begin{array}{l}\text { Gain Scores From pre-test } \\
\text { to post-test }\end{array}$ & $\begin{array}{l}\text { Equal variances } \\
\text { assumed }\end{array}$ & 0.06 & 0.80 & 3.78 & 8.00 & 0.00 & 1.05 & 1.55 & 6.44 \\
\hline & $\begin{array}{l}\text { Equal variances } \\
\text { not assumed }\end{array}$ & & & 0.61 & 7.95 & 0.56 & 1.32 & 1.54 & 6.45 \\
\hline $\begin{array}{l}\text { Gain scores from post-test } \\
\text { to Delayed post-test }\end{array}$ & $\begin{array}{l}\text { Equal variances } \\
\text { assumed }\end{array}$ & 0.23 & 0.65 & 0.61 & 8.00 & 0.56 & 1.32 & -2.24 & 3.84 \\
\hline & $\begin{array}{l}\text { Equal variances } \\
\text { not assumed }\end{array}$ & & & 0.61 & 7.95 & 0.56 & 1.32 & -2.25 & 3.85 \\
\hline
\end{tabular}


Following Krashen's theory, in order to facilitate the students' needs and to decrease the drawbacks of being in an English group class, different strategies were applied to both groups such as using games, motional activities, and singing songs to provide them with a friendly environment, increase their motivation, and decrease their anxiety. The result of this study was further proof of Krashen's theory, since both the experimental group and the control group showed improvements after the intervention across time, which could be due to their increased motivation to participate in the class. However, the RALL group outperformed the non-RALL group because NIMA was more interesting to the participants than the human teacher.

On the other hand, according to Hatch and Brown (1995), vocabulary learning has five steps: source, a clear image, learning, a strong memory and usage. These steps need to be taken more carefully with learners with DS since one of their main characteristics is their delay in speech and language learning (Abbeduto \& Chapman, 2005; Chapman, 2003; Chapman \& Hesketh, 2000), which highlights the importance of applying an effective teaching technique. Therefore, in this study, the vocabularies were selected based on the participants' needs and different materials, such as flashcards, pictures, and real objects, were used to provide a clear image of the vocabulary. This teaching technique is also based on the fact that individuals with DS perform better through visual activities rather than verbal ones since they experience verbal short-term memory delay which makes them less capable of remembering the words (Jarrold, Baddeley, 2001). Moreover, aligned with the intentional vocabulary learning suggested by Read (2004), the vocabularies were taught explicitly using repetition and rehearsal. Repetition strategy, as suggested by Buckley (2002), is an effective strategy for these people to learn new words and also to improve their short-term memory abilities.

As the results of this study revealed, the RALL group significantly outperformed the non-RALL group in their post-test performance. Since, the robot as a teacher-assistant was the only difference between the two groups, it can be said that the significant improvement of the RALL group on the post-test could be due to the presence of the robot. According to Thurn (2004), robots have the advantage of being autonomous and interactive with humans, which is an important factor in language teaching. In case of people with DS who are known as good communicators, this fact could help the participants in this study to do their best to make short conversations and interaction in English due to the fact that they knew the robot as a native speaker. Fink (2012) also posits the ability of robots to provide human robot interaction (HRI) as an advantage. As observed in the class, the RALL group showed more motivation to communicate in English and interact with their classmates or the robot, which is aligned with communicative language teaching (CLT). They enjoyed having individual or group activities with the robot using English vocabulary. This fact shows that they accepted the robot as a member of the class and tried to attract the robot's attention and follow his instructions.

Additionally, this finding supports the results from the study by the Alemi, Meghdari, \& Haeri (2017) who investigated 19 preschool Iranian EFL learners' attitude towards RALL instruction. Their results indicated an increase in children's motivation by interacting with the robot and a decrease in their anxiety due to the friendly atmosphere provided in the class with the robot. Although the pace and retention is higher among ordinary individuals, still the performance of RALL group is better comparing to nonRALL group even among individuals with intellectual disabilities. 
It also supports the findings of the study conducted by the Alemi $(2015 \mathrm{a}, \mathrm{b})$ which found positive effects of RALL instruction on English vocabulary learning and motivation among autistic children. In the case of preschoolers, the sessions were based on different designed roles such as gaming role, encouraging, noticing, calling out children's names and signing songs. The results were analyzed based on the amount of talking to robot, their eagerness to attract the robot's attention, and also their engagement with the robot. In the case of autistic learners and also those with DS participated in this study, the same techniques were applied to integrate the language learning with series of fun activities and scenarios to motivate learners to interact with the robot and to be less distracted. Although in this study both groups had the advantage of being involved in different games designed based on the English vocabulary, the RALL group showed more eagerness to play with NIMA and to have face to face interaction with him, touch him, or listen to him in the class. This is in line with the results of Lehman, Iacono, Dautenhahn, Marti, and Robins (2014) who indicated improvement in the social skills of a child with Down syndrome by applying different games via preprogrammed scenarios using the humanoid robot KASPAR and the mobile robotic platform IROMEC. In fact, the humanoid robot could encourage a child with DS for more interaction and communication like what we observed in our study.

This also supports the results gained from previous research conducted on autistic children indicating the positive effects NAO and Alice robots had on autistic children's motivation to participate in the therapeutic sessions by improving their eye-contact abilities and eagerness to interact with the robots (Alemi, Meghdari, Pouretemad, \& Taheri, 2013a; Alemi, Meghdari, \& Taheri, 2013b). In the present study, more motivation to learn English has also been observed in RALL group, and it is evident that humanoid robots can attract individuals with intellectual disabilities better than human beings do.

As mentioned earlier, remembering the words is one of the steps in vocabulary learning and this is an important issue in the case of people with DS. As suggested by Buckley (2002), repetition is an effective strategy for these people to learn new words and also to improve their short-term memory abilities. This strategy aligned with using flashcards, pictures or real objects in both groups to make them use of their visual memory rather than their verbal one. In this study, to increase the retention of the taught vocabularies, the repetition technique was used in teaching sessions integrated with different activities such as miming and repeating the vocabularies after the robot. According to Allen (1995), vocabulary retention increases when taught with gestures. Therefore, in some cases, the teacher would use gestures to help students remember a specific word. This agrees with the findings of Adamson, Bakeman, and Brandon's (2015) study on toddlers with DS and autism which proved the importance of such activities in addition to the help of their parents on the participants' language development. According to the video recordings, although both groups favored the imitation strategy, participants in the RALL group were more motivated to imitate NIMA's gestures and movements especially when teaching verbs. This could be due to the toy-like appearance of the robot which may make the students more interested and eager to follow the instruction. This fact could also explain the more satisfying results that the RALL group had in their delayed-post-test. The results are compatible with the findings of Macedonia, Muller, and Friederici (2011) which revealed that meaningful gestures help learners to significantly better retain the verbal material over time. 
Another reason that could affect the memorization of the vocabulary could be learning the words through real-life scenarios which were designed and programmed into the robot. Participants enjoyed watching NIMA acting and using vocabulary they could understand in the class. This increased their motivation to follow the lines and try to understand what NIMA was saying. As some of the vocabulary in the syllabus (adjectives in this case) were used as positive feedback by NIMA or the teacher in most of the teaching sessions, we can say that this positive feedback repetition also encouraged the participants to use the words and also helped them to acquire the words. In the RALL group, however, students tried harder to attract NIMA's attention by giving correct answers or showing their abilities to speak English in the class. Therefore, considering the problems these individual face in verbal short-term memory, it can be stated that the better retention in the RALL group's performance on the delayed post-test could be due to the existence of the robot which also provides further evidence on the findings of the Alemi, Meghdari, \& Ghazisaedy (2014) on junior high school students and also that of the Alemi (2015a, b) on autistic children which revealed the positive effects of RALL on English vocabulary retention.

It should be noted that RALL instruction like any other teaching techniques had some disadvantages as observed in the class. For instance, in some cases, students would come to the robot to have a spontaneous conversation which was not possible if the conversations were not programmed into the robot and this would disappoint them. In some other cases, students saw the robot more as an entertainer than a teacher-assistant, which could make them take the class less serious.

\section{Conclusion}

Individuals with Down syndrome have some issues in learning due to their cognitive delay, such as low short-term memory, problems with pronouncing and uttering the words, which can affect their learning process. Regarding the effect of utilizing a humanoid robot in English vocabulary learning and retention, we can say that long-term instruction with the assistance of a humanoid robot can help students be more interactive in a natural and native-like situation and have more interest and motivation in the class. The repetition strategy used in this study in the teaching scenarios in addition to the games and motional activities also helped the participants to remember the taught vocabulary in different contexts and situations. The humanoid robot with its friendly and childish tone of voice and also the feedback the students received from it helped the students to have more interaction with the robot and follow the instructions. Using the robot as a teacher-assistant also allowed the teacher to pre-program the robot with different games along with some motions. Therefore, the students would be more motivated and enjoy learning through communicating with the robot. It can be stated that the presence of the robot in the class was a new experience which also helped students to be less distracted. For example, they would show more attention to the class when the robot would speak and say the vocabulary. They would also show more competitiveness when the aim was to play a game with the robot. The main results of this case study show that these factors align with the main factors in learning a second language and are the result of applying technology in the classes. Due to the interest of young learners with DS in technology, schools and other institutes should apply new teaching trends and strategies from the first levels of education to help these 
students be more interested and motivated and also increase their cognitive abilities. It can be said that the findings of this study can contribute to institutes and schools for people with Down syndrome and also other qualitative research on their cognitive abilities. However, due to the limitations we had like the number of participants and teaching sessions, more research needs to be done focusing on English teaching and learning for people with DS with a larger number of participants and longer period of classes. However, this study was the first small step toward applying a robot to help Iranian individuals with DS to learn English vocabulary easier. Due to the fact that the focus of this study was on English vocabulary learning, other research can focus on more qualitative research questions such as applying this trend to improve cognitive abilities among these people in order to facilitate and motivate them to learn a language. Furthermore, psychological studies can be done to examine the effect of applying a humanoid robot on motivation, self-confidence and other psychological factors among people with Down syndrome to facilitate learning and fulfill their needs in their educational and social life.

\title{
Additional file
}

Additional file 1: English Tests. (DOCX $517 \mathrm{~kb}$ )

\section{Acknowledgements}

We appreciate Social \& Cognitive Robotics Laboratory, Center of Excellence in Design, Robotics, and Automation (CEDRA), Sharif University of Technology, Tehran, Iran for providing us the facilities to do this research.

\begin{abstract}
About the authors
Minoo Alemi is Associate Professor of Applied Linguistics at Islamic Azad University, West Tehran Branch. She is the associate editor of Applied Pragmatics (John Benjamins) and sits on the editorial/review boards of many journals. Moreover, she is associate researcher at CEDRA, Sharif University of Technology, Iran. Her areas of interest include L2 pragmatic instruction \& assessment, technology enhancement education, teacher education, and ESP. She has also published over 70 papers in different journals such as Journal of Intercultural Communication Research, The Asia-Pacific Education Researcher, Language and Intercultural Communication, TESL-EJ, TESL Canada Journal, The RELC Journal, and International Journal of Social Robotics.

Shirin Bahramipour holds an M.A in TEFL from Islamic Azad University, West Tehran Branch, Iran. She has been teaching English for 10 years in Iran.
\end{abstract}

\section{Authors' contributions}

MA conceived of the study and decided on research questions, types of participants, instrumentation, data collection procedure, and data analysis. MA also supervised the data collection and analysis procedures and helped draft and finalize the manuscript. ShB collected and analyzed the data and drafted the manuscript. Both MA and ShB read and approved the final manuscript.

\section{Funding}

There were no sources of funding for the research reported in this manuscript.

Availability of data and materials

"Please contact authors for data requests."

Competing interests

The authors declare that they have no competing interests.

\section{Author details}

'Department of English Language Teaching, Faculty of Humanities, Islamic sAzad University, West Tehran Branch, Simaye Iran Ave, Tehran, Iran. ${ }^{2}$ Islamic Azad University, West Tehran Branch, Tehran, Iran.

Received: 16 April 2019 Accepted: 28 July 2019

Published online: 13 September 2019

\section{References}

Alemi, M., Anani Sarab, MR., \& Lari, Z. (2012). Successful learning of academic word list via MALL.International Education Studies, 5(6),99 109 
Alemi, M., Meghdari, A., Pouretemad, H.R., \& Taheri, A.R. (2013a). Clinical Application of a Humanoid Robot in Playing Imitation Games for Autistic Children in Iran. Paper presented at the 2nd Basic Clinical and Neuroscience Congress, Tehran, Iran.

Alemi, M., Meghdari, A., \& Taheri, A.R. (2013b). The Effects of Using Humanoid Robots for Treatment of Individuals with Autism in Iran. Paper presented at the 6th Neuropsychology Symposium, Tehran, Iran.

Alemi, M., Meghdari, A., \& Ghazisaedy, M. (2014). Employing humanoid robots for teaching English language in Iranian junior high-Schools. International Journal of Humanoid Robotics, 11(03), 1450022. https://doi.org/10.1142/S0219843614500224.

Alemi, M., Meghdari, A., Basiri, N. M., \& Taheri, A. (2015a). The effect of applying humanoid robots as teacher assistants to help Iranian autistic pupils learn English as a foreign language. In International Conference on Social Robotics (pp. 1-10). Springer, Cham.

Alemi, M., Meghdari, A., \& Ghazisaedy, M. (2015b). The impact of social robotics on L2 learners' anxiety and attitude in English vocabulary acquisition. International Journal of Social Robotics, 7(4), 523-535.

Alemi, M., Meghdari, A., \& Haeri, N. S. (2017). Young EFL Learners' Attitude Towards RALL: An Observational Study Focusing on Motivation, Anxiety, and Interaction. In International Conference on Social Robotics (pp. 252-261). Springer, Cham.

Abbeduto, L., Chapman, R. S., Fletcher, P., \& Miller, J. (2005). Language development in Down syndrome and fragile X syndrome. Trends in language acquisition research, 4, 53-72.

Adamson, L. B., Bakeman, R., \& Brandon, B. (2015). How parents introduce new words to young children: The influence of development and developmental disorders. Infant Behavior and Development., 39, 148-158.

Allen, L. Q. (1995). The effects of emblematic gestures on the development and access of mental representations of French expressions. The Modern Language Journal., 79(4), 521-529.

Bray, M., \& Woolnough, L. (1988). The language skills of children with Down syndrome aged 12 to 16 years. Child Language Teaching and Therapy., 4, 311-324.

Brown, R., Waring, R., \& Donkaewbua, S. (2008). Incidental vocabulary acquisition from reading, reading-while-listening, and listening to stories. Reading in a foreign language., 20(2), 136-163.

Buckley, S. (2002). The significance of early reading for children with Down syndrome. Down Syndrome News and Update., 2(1), 1-1. https://doi.org/10.3104/practice.152.

Chang, C. W., Lee, J. H., Chao, P. Y., Wang, C. Y., \& Chen, G. D. (2010). Exploring the possibility of using humanoid robots as instructional tools for teaching a second language in primary school. Educational Technology \& Society., 13(2), 13-24.

Chapman, R. S. (2003). Language and communication in individuals with Down syndrome. International review of research in mental retardation, 27, 1-34.

Chapman, R. S., \& Hesketh, L. J. (2000). Behavioral phenotype of individuals with Down syndrome. Developmental Disabilities Research Reviews, 6(2), 84-95.

Cummins, J. (2000). Language, power, and pedagogy: Bilingual children in the crossfire (vol.23). Multilingual matters.

Dautenhahn, K., \& Billard, A. (2002). Games children with autism can play with robots, a humanoid robotic doll. Universal access and assistive technology, 179-190. https://doi.org/10.1007/978-1-4471-3719-1_18.

Fink, J. (2012). Anthropomorphism and human likeness in the design of robots and human-robot interaction. In International Conference on Social Robotics (pp. 199-208). Springer Berlin Heidelberg.

Gass, S., \& Selinker, L. (2008). The role of the native language: An historical overview. Second language acquisition: an introductory course. New York: Tayler \& Francis, 89-120.

Goodrich, M. A., \& Schultz, A. C. (2007). Human-robot interaction: A survey. Foundations and Trends in Human-Computer Interaction, 1(3), 203-275.

Han, J. (2010). Robot-aided learning and r-learning services. In D. Chugo (Ed.), human-robot interaction. Retrieved from: http://www.intechopen.com.

Han, J. (2012). Emerging technologies - robot assisted language learning. Language Learning \& Technology, 16(3), 1-9. Retrieved from http://dx.doi.org/10125/44291.

Hatch, E., \& Brown, C. (1995). Vocabulary, semantics, and language education. New York: Cambridge University Press.

Hegarty, M. (2004). Dynamic visualizations and learning: Getting to difficult questions. Learning and Instruction, 14, $343-351$.

Holden, C., \& Sykes, J. M. (2013) Complex L2 pragmatic feedback via place-based mobile games. Technology in interlanguage pragmatics research and teaching, 155-184.

Hyun, E. J., Kim, S. Y., Jang, S., \& Park, S. (2008) Comparative study of effects of language instruction program using intelligence robot and multimedia on linguistic ability of young children. In Robot and Human Interactive Communication, 2008. RO-MAN 2008. The 17th IEEE International Symposium, 187-192.

Jarrold, C., \& Baddeley, A. (2001). Short-term memory in Down syndrome: Applying the working memory model. Down Syndrome Research and Practice., 7(1), 17-23.

Kanda, T., Hirano, T., Eaton, D.,Ishiguro,H., (2004). Interactive robots as social partners and peer tutors for children: A Field Trial. Human Comp. Interact. 19: 61-84.

Krashen, S. (1982). Principles and practice in second language acquisition. Oxford: Pergamon Press.

Lee, S., Noh, H., Lee, J., Lee, K., Lee, G. G., Sagong, S., \& Kim, M. (2011). On the effectiveness of robot-assisted language learning. ReCALL, 23(1), 25-58. https://doi.org/10.1017/S0958344010000273.

Leeke, P., \& Shaw, P. (2000). Learners' independent records of vocabulary. System, 28(2): 271-289.

Lehmann, H., lacono, l., Dautenhahn, K., Marti, P., \& Robins, B. (2014). Robot companions for children with Down syndrome: A case study. Interaction Studies, 15(1), 99-112.

Macedonia, M., Müller, K., \& Friederici, A. D. (2011). The impact of iconic gestures on foreign language word learning and its neural substrate. Human Brain Mapping, 32(6), 982-998.

Park, S. J., Han, J. H., Kang, B. H., \& Shin, K. C. (2011) Teaching assistant robot, ROBOSEM, in English class and practical issues for its diffusion. In Advanced robotics and its social impacts (ARSO). 2011 IEEE workshop, 8-11. Menlo Park, CA: IEEE.

Patterson, D. (2009). Molecular genetic analysis of Down syndrome. Human Genetics, 126(1), 195-214. https://doi.org/10.1007/ s00439-009-0696-8.

Read, J. (2004). Research in teaching vocabulary. Annual Review of Applied Linguistics, 24(1), 146-161.

Sandall, S. R., \& Schwartz, I. S. (2002) Building blocks for teaching preschoolers with special needs. Paul H. Brookes publishing CO., PO Box 10624, Baltimore, MD 21285-0624.

Schmitt, N., \& McCarthy, M. (1997). Vocabulary: Description, acquisition and pedagogy. Cambridge university press. 
Taguchi, N., \& Sykes, J. M. (2013) Introduction: Technology in interlanguage pragmatics research and teaching. In N. Taguchi \& J. M. Sykes (Eds.). Technology in interlanguage pragmatics research and teaching (pp. 1-18). John Benjamins Publishing Thurn, S. (2004). Toward a framework for human-interaction. Human-Computer Interaction, 19(1), 9-24.

Xie, L., Antle, A. N., \& Motamedi, N., (2008, Febuary) Are tangibles more fun? Comparing children's enjoyment and engagement using physical, graphical and tangible user interfaces. In TEl '08: Proceedings of the 2nd international conference on tangible and embedded interaction, 191-198. New York: ACM.

Yoder, P. J., Woynaroski, T., Fey, M. E., Warren, S. F., \& Gardner, E. (2015). Why dose frequency affects spoken vocabulary in preschoolers with Down syndrome. American journal on intellectual and developmental disabilities, 120(4), 302-314.

\section{Publisher's Note}

Springer Nature remains neutral with regard to jurisdictional claims in published maps and institutional affiliations.

Submit your manuscript to a SpringerOpen ${ }^{\circ}$ journal and benefit from:

- Convenient online submission

- Rigorous peer review

- Open access: articles freely available online

High visibility within the field

- Retaining the copyright to your article

Submit your next manuscript at $\boldsymbol{\nabla}$ springeropen.com 